Research Article

\title{
Study on the Component-Based Model of an All-Welded Beam-Column Connection for Progressive Collapse Analysis
}

\author{
Fuzhe Xie $\mathbb{D}^{1},{ }^{1}$ Wenyuan Liu $\mathbb{D D}^{2},{ }^{2}$ Bin Gu $\mathbb{D}^{1},{ }^{1}$ and Hai Qian $\mathbb{D}^{1}$ \\ ${ }^{1}$ Faculty of Civil Engineering and Mechanics, Jiangsu University, Zhenjiang 212013, China \\ ${ }^{2}$ Taizhou Institute of Science and Technology, Nanjing University of Science and Technology, Taizhou 225300, China \\ Correspondence should be addressed to Fuzhe Xie; xiefuzhe@ujs.edu.cn
}

Received 27 August 2020; Revised 4 October 2020; Accepted 30 October 2020; Published 16 November 2020

Academic Editor: Jiang Jin

Copyright (c) 2020 Fuzhe Xie et al. This is an open access article distributed under the Creative Commons Attribution License, which permits unrestricted use, distribution, and reproduction in any medium, provided the original work is properly cited.

The mechanical behavior of all-welded beam-column connections of steel frames during progressive collapse was numerically studied using finite element simulations. The validation of the numerical model was based on a previous test model. The analysis results indicated that the stiffness of the all-welded beam-column connection in the elastic-plastic stage was mainly provided by the shear stiffness of the panel zone, and the axial compression on the column had a substantial impact on the capacity and ductility of the all-welded beam-column connection. An improved component-based model of the all-welded beam-column connection was proposed. To verify the accuracy of the proposed model, a beam-column assembly with an all-welded connection was established and the influence of the catenary action, column axial compression, beam-column stiffness ratio, and dynamic performance was parametrically analyzed. The validation results showed that the proposed model was able to simulate the behavior of all-welded beam-column connections at large structural deformation.

\section{Introduction}

Progressive collapse occurs when an initial local failure spreads disproportionately, resulting in total collapse or the collapse of a disproportionately large part of a structure. Although the progressive collapse of a structure is a rare event, it may result in substantial casualties and considerable economic losses when it occurs. The partial collapse of the Ronan Point apartment building in 1968 in London triggered the investigation of structural progressive collapse [1,2], and substantive studies [3-7] have been carried out since the collapse of the World Trade Center towers in 2001.

Many research results have shown that the performance of beam-column connections is essential in the prevention of the progressive collapse of steel frames [8-10]. A large number of studies on beam-column connections were also conducted, including experiments and numerical and theoretical analyses [11-13]. Lew et al. [14] carried out a "pushdown" experiment on two full-scale steel beam-column assemblies to investigate the performance of moment connections with welded flange and bolted web under a column-removal scenario. Tang et al. [15] conducted an experimental and numerical study on a fully bolted connection in a reinforced concrete column and steel beam frame structure to investigate the response characteristics of beam-column connections under asymmetric collapse. Dinu et al. [16] experimentally studied the behaviors of four types of beam-column connections during the structural collapse and compared them with the requirements of seismic codes. Zhong et al. [17] conducted a static experiment on three composite beam-column assemblies with unequal spans and numerically analyzed the test model. The results indicated that the concrete slabs and beam span had obvious influences on the structural collapse resistance. Stylianidis and Nethercot [18] theoretically derived a beam-column connection with the component method and validated the proposed model based on the results obtained from relevant tests. Yim and Krauthammer [19] analyzed the mechanical properties of a single-plate shear connection and proposed a simplified connection model using the component method. The numerical analysis results showed that the proposed 
model worked well under monotonic, cyclic loading and blast loads.

The all-welded beam-column connection (both the flange and web of the beam are welded to the column, as shown in Figure 1(b)) is a widely used connection in steel frames. The mechanical behavior of an all-welded beamcolumn connection under small structural deformation has been substantially studied $[20,21]$. However, limited studies have been conducted on the performance of all-welded beam-column connections during the process of structural collapse. Qian et al. [22] conducted an experimental and numerical study on the collapse resistance of a two-story steel frame with two types of all-welded connections. The results indicated that the welded connection with the reduced beam section exhibited better performance when the structure undergoes large deformation. Yang et al. [23] numerically analyzed the dynamic behavior of all-welded beam-column connections under impact loading. Lee et al. [24] proposed two simplified methods to evaluate the progressive collapse potential of steel frames with all-welded beam-column connections.

Currently, there are many progressive collapse studies on bolt connections, and various component-based joint models have been established for simplifying the progressive collapse analysis of steel frames. However, studies on the performance of all-welded beam-column connections under large structural deformation are limited. Many available component-based models of all-welded beam-column connections, which are derived based on the case of small structural deformation, are not suitable for the progressive collapse analysis.

In this study, the mechanical behavior of an all-welded beam-column connection during large structural deformation was investigated based on a previous test model. An improved component-based model of the all-welded beamcolumn connection was proposed. The accuracy of the proposed model was validated considering the influence of the catenary action, column axial compression, the beamcolumn stiffness ratio, and dynamic loading, separately.

\section{Test Model and Finite Element Analysis}

2.1. Test Model. The mechanical behavior of the targeted connection under large structural deformation was analyzed through a finite element investigation. The numerical model was developed and validated based on a previous testing program for an all-welded beam-column connection in [25].

As shown in Figure 1(a), the test model of [25] consisted of a beam ( $1.45 \mathrm{~m}$ in length) and a column ( $2.75 \mathrm{~m}$ in height). The column was composed of three parts using flanges to connect them together. Both ends of the column were hinged so that the column was able to rotate freely but could not move horizontally. There were also out-of-plane supports at the ends of the beam and column to prevent the outof-plane instability of the test model. The beam was completely welded to the column, as shown in Figure 1(b).

A compression force $P_{c}(500 \mathrm{kN})$ was exerted on the top of the column, and a cyclic reversed load $\left(P_{b}\right)$ was applied at the beam end by a Jack (the loading scheme is shown in
Figure 2). Both the beam and column sections were $\mathrm{H}$-section, and the sizes are shown in Table 1. Table 2 shows the material properties of the beam and column.

2.2. The Finite Element Analysis. To verify the test results and facilitate further parametric analyses, a shell element model was constructed in accordance with the test model using the software Abaqus, as shown in Figure 3. The in-plane support of the column was simulated using a beam element with the same axial rigidity $(E A)$ as that of the test apparatus, and the contact elements were set between the flanges to simulate the behavior of the flange connections. The types of shell elements were S4R and S3, and the mesh size of the elements near the beam-column connection was $25 \mathrm{~mm}$, which was approximately half of the mesh size in the other area. The ductile damage mode in Abaqus was used to simulate the fracture of structural members [26], and the elongation $\varepsilon_{u}$ in Table 2 was chosen as the fracture strain.

The force-displacement hysteretic curve (Figure 4) obtained by analyzing the shell element model with the static nonlinear analysis method was compared to the test results. In Figure $4, P_{b}$ represents the cyclic reversed load at the beam end, and $\Delta$ is the vertical displacement of point $A$ in Figure 1(a).

As depicted in Figure 4, the results (such as stiffness, capacity, and the corresponding displacement) of the finite element (FE) model were close to that of the test specimen; some differences were mainly caused by the initial defects, such as the residual stress of the test members and the inevitable eccentricity in the actual loading process [27]. Therefore, the FE model can accurately simulate the behavior of the experimental connection.

2.3. Mechanical Behavior of the All-Welded Connection during Large Structural Deformation. The mechanical behavior of the all-welded beam-column connection under large structural deformation was investigated based on modifying the shell element model above: (a) changing the cyclic load $P_{b}$ (Figure $\left.1(\mathrm{a})\right)$ to a vertical downward load $\left(F_{v}\right)$ at the end of the beam and (b) removing of the flange connections of the column and substituting the in-plane support with ideal rigid constraint to neglect the influence of the defects.

Figure 5 shows the deformation of the T-shaped structure when the free end of the beam reaches a vertical displacement of $350 \mathrm{~mm}$. It is evident that the beam-column connection develops an obvious deformation, which mainly includes the bending rotation of the column flange at four corner points and the shear deformation of the panel zone, while the latter is the dominant deformation because the angle of the shear deformation is 20 times greater than the bending rotation angle.

However, the connection cannot develop such an obvious deformation in all cases when considering the influence of the axial compression on the column. The column compression of the above model is $500 \mathrm{kN}$, which is approximately $0.2 P_{y c}\left(P_{y c}\right.$ is the yield force of the column). To study the behavior of the all-welded beam-column connection under various conditions, the column compression 


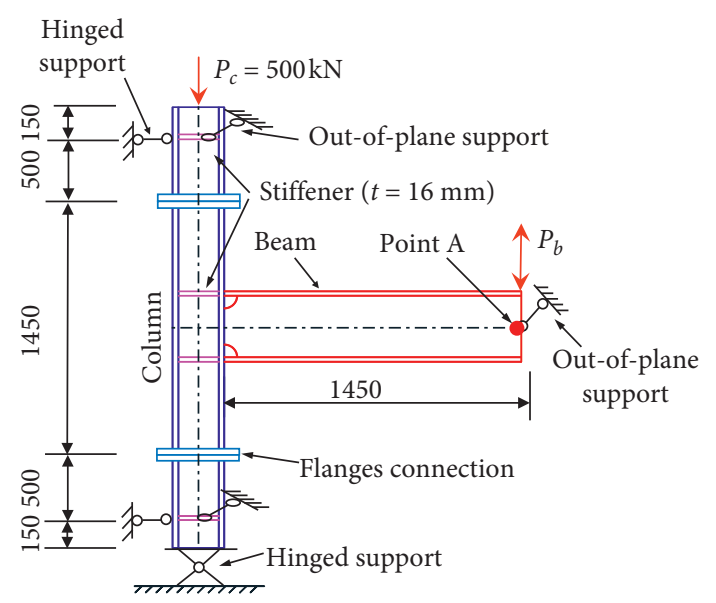

(a)

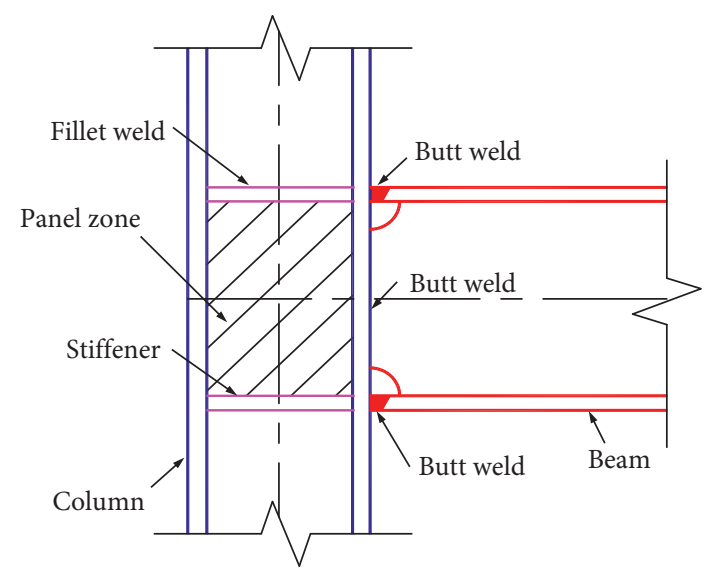

(b)

FIgUre 1: Test model and details of the connection. (a) Test model (length unit: mm). (b) Details of the all-welded connection.

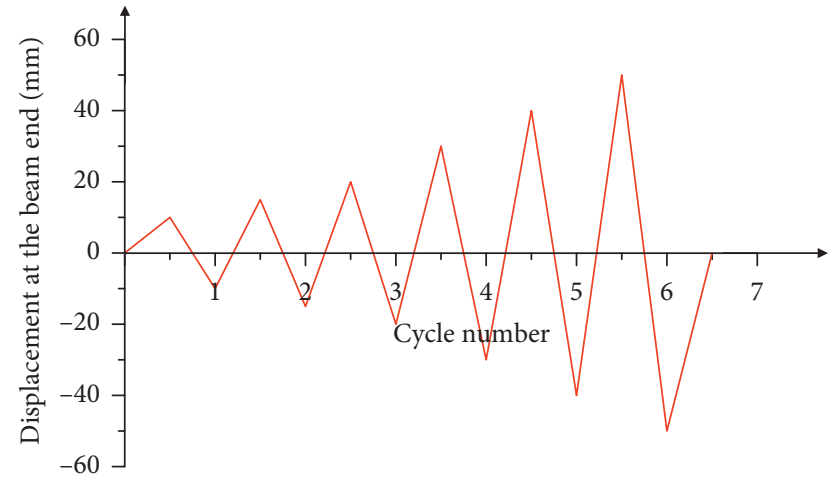

Figure 2: The cyclic reversed loading scheme.

Table 1: Section sizes of the beam and column (unit: $\mathrm{mm}$ ).

\begin{tabular}{lcccc}
\hline & \multicolumn{2}{c}{ Flange } & \multicolumn{2}{c}{ Web } \\
& Width & Thickness & Height & Thickness \\
\hline Beam & 146 & 11.92 & 352 & 7.76 \\
Column & 251 & 15.50 & 250 & 9.92 \\
\hline
\end{tabular}

TABLE 2: Material properties of the beam and column.

\begin{tabular}{lcccc}
\hline & $E(\mathrm{GPa})$ & $f_{y}(\mathrm{MPa})$ & $f_{u}(\mathrm{MPa})$ & $\mathcal{\varepsilon}_{u}$ \\
\hline Beam flange & 206 & 294 & 492 & 0.203 \\
Beam web & 206 & 254 & 416 & 0.222 \\
Column flange & 206 & 244 & 383 & 0.2 \\
Column web & 206 & 262 & 424 & 0.21 \\
Butt weld & 206 & 293 & 453 & 0.131 \\
\hline
\end{tabular}

Note: $E$ is the elastic modulus; $f_{y}$ is the yield stress; $f_{u}$ and $\varepsilon_{u}$ are the ultimate stress and strain, respectively.

of the shell element model was separately changed to $0,0.5$, and $0.7 P_{y c}$, and the load to vertical displacement curves was compared in Figure 6.

According to the GSA specification [28], the steel beam is considered to fail when the rotational angle of the beam to the column is more than $12^{\circ}$. Therefore, the vertical

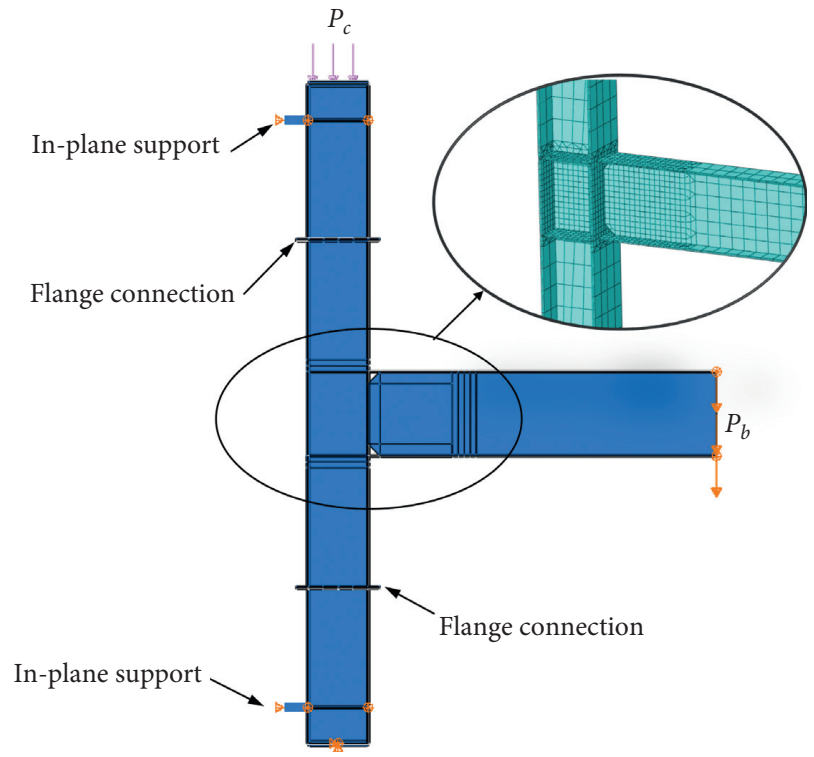

Figure 3: The shell element model.

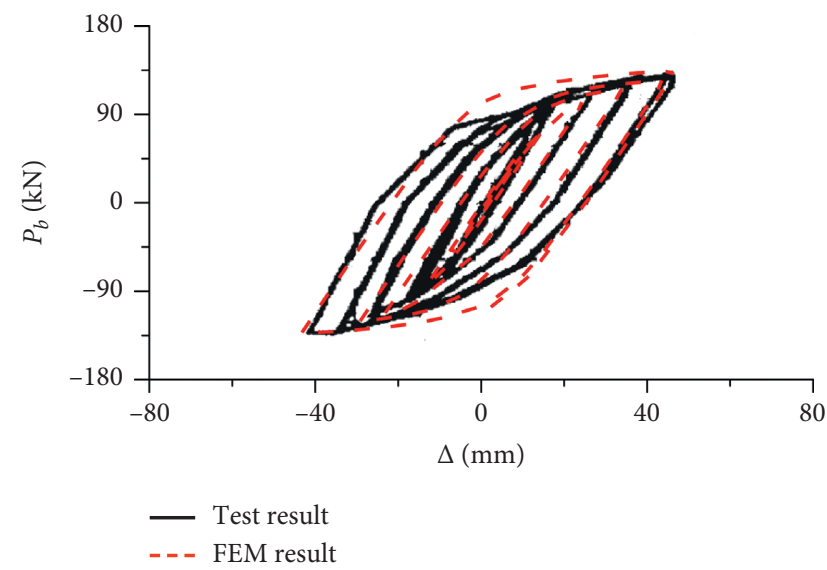

Figure 4: Comparison of the hysteretic curves. 


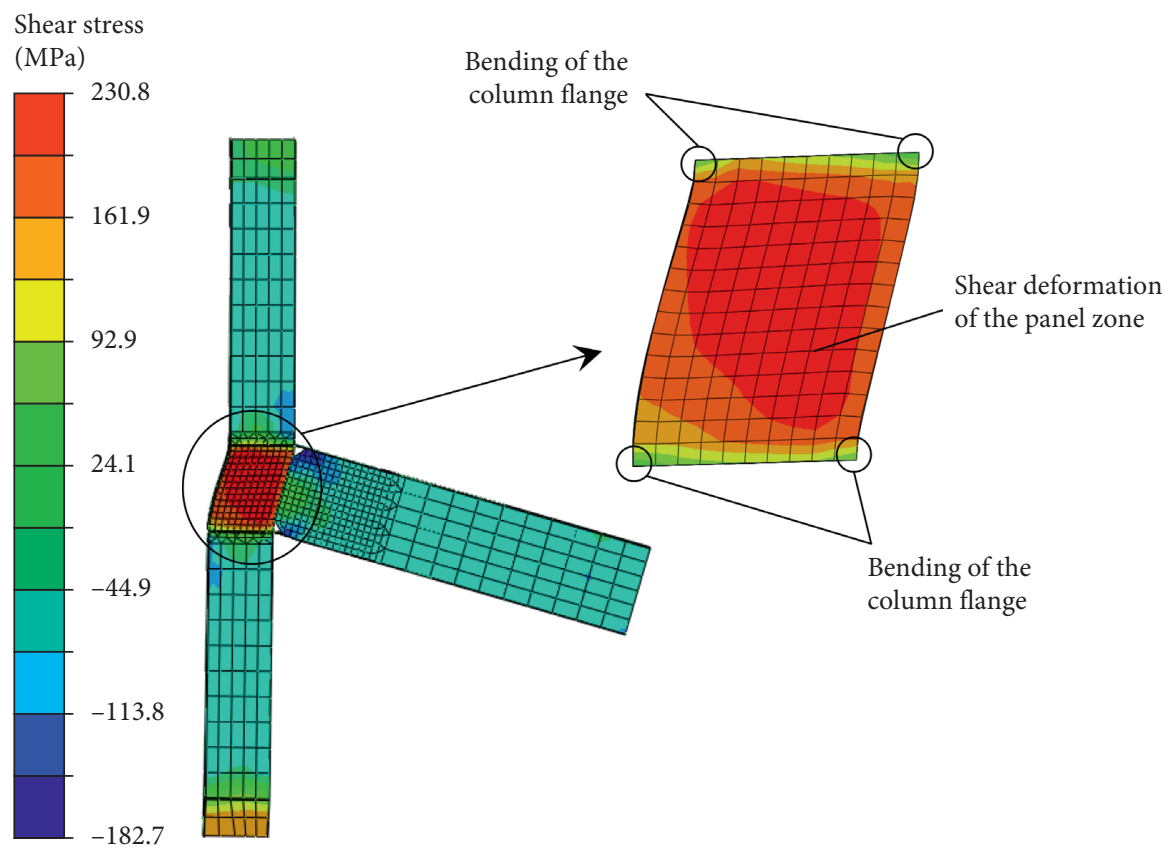

Figure 5: Deformation of the beam-column connection $\left(P_{c}=0.2 P_{y c}\right)$.

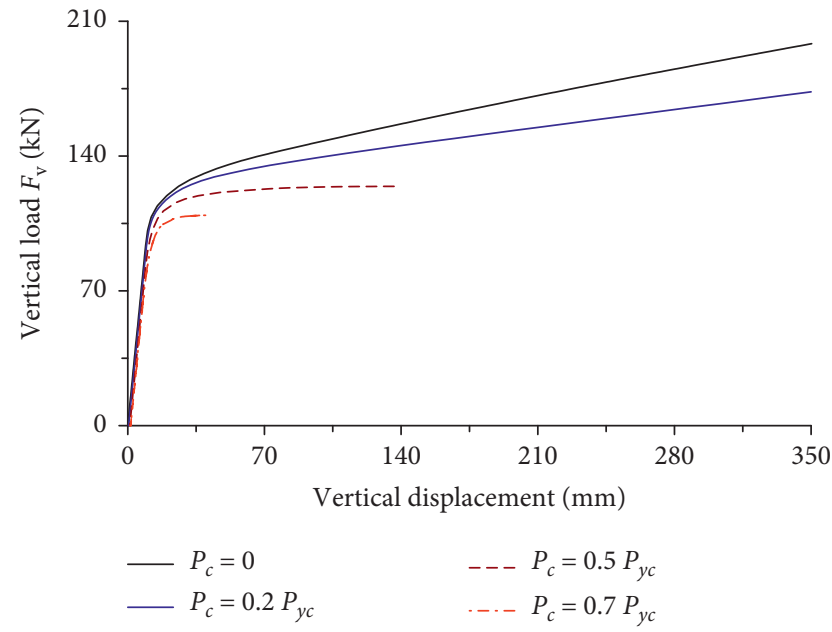

Figure 6: Load to vertical displacement curves for various conditions of column compression.

displacement at the free end of the beam was no more than $350 \mathrm{~mm}$ (the corresponding angle is $12.5^{\circ}$ ) when analyzing the shell element model.

Figure 6 indicates that the deformability of the beamcolumn joint decreases as the column compression increases. Taking the $0.7 P_{y c}$ case as an example, when the vertical displacement of the beam end reaches $40 \mathrm{~mm}$, a plastic hinge forms in the column that makes the T-shaped structure unstable. As a result, when the T-shaped structure fails, the deformation of the beam-column connection is very small (most is the shear deformation of panel zone) compared to that of $0.2 P_{y c}$ case, as shown in Figure 7. Similar behavior of the beam-column connection takes place in the case of $0.5 P_{y c}$.

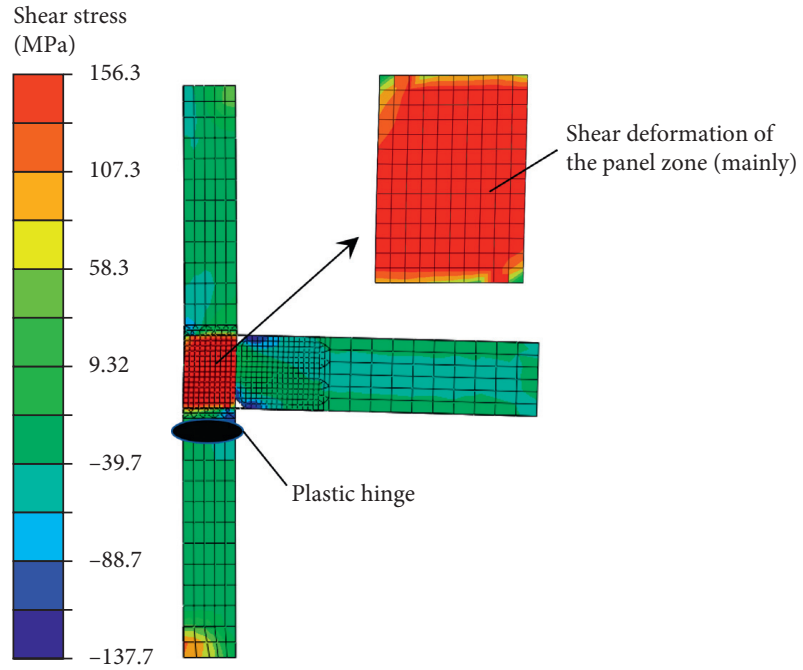

Figure 7: Deformation of the beam-column connection $\left(P_{c}=0.7\right.$ $\left.P_{y c}\right)$.

The capacity of the beam-column connection, which is always reflected by the yield moment $M_{y j}$, also decreases as the column compression increases. In theory, the reduction effect of the column compression on the yield moment can be considered by multiplying $M_{y j 0}$, which is the yield moment of the beam-column connection when the compression is 0 , by a factor $\alpha$ [20] that is given as

$$
\alpha=\sqrt{1-\left(\frac{P_{c}}{P_{y c}}\right)^{2}} .
$$

The yield moment reduction factors of the shell element model under different column compression $\alpha_{\text {SEM }}$ are 
compared with the results of formula (1), as shown in Table 3. The comparison results indicate that formula (1) can accurately predict the influence of the column pressure when the level of $P_{c}$ is small. However, the results of formula (1) are increasingly inconsistent with those of the shell element model as $P_{c}$ increases, especially when $P_{c}$ is larger than 0.5 $P_{y c}$.

\section{Component-Based Model of the All-Welded Beam-Column Connection}

3.1. A Component-Based Model. The component-based models of beam-column connections are widely used in seismic and collapse analyses for their predominant performance on the simulation of connections. A componentbased model of a beam-column connection is usually composed of beam elements and spring elements according to the connection form, size, and loading condition. There are limited component-based models for all-welded beamcolumn connections at present. Krawinkler [20] proposed a component-based model for all-welded beam-column connections based on experimental results. The model (referred to as "KCM") consists of four rigid beam elements and four rotation springs at the corners, as shown in Figure 8.

The behavior of the KCM is determined by the four rotation springs that have nonlinear properties. The stiffness and capacity of the springs are shown in

$$
\begin{aligned}
k= \begin{cases}k_{e}=0.95 d_{b} d_{c} t G, & \left(0<\gamma \leq \gamma_{y}\right), \\
k_{p k}=0.421 E b_{c} t_{c f}^{2}, & \left(\gamma_{y}<\gamma \leq 4 \gamma_{y}\right), \\
0 & \left(4 \gamma_{y}<\gamma\right),\end{cases} \\
M_{y}=0.55 d_{b} d_{c} t f_{y}, \\
M_{p}=0.55 d_{b} d_{c} t f_{y}\left(1+\frac{3.45 b_{c} t_{c f}^{2}}{d_{b} d_{c} t}\right),
\end{aligned}
$$

where $k_{e}$ is the elastic stiffness of the spring; $k_{\mathrm{pk}}$ is the postelastic stiffness of the spring; $\gamma$ is the rotation angle of the spring; $\gamma_{y}$ is the yield shear angle of the panel zone; $M_{y}$ is the moment when $\gamma$ reaches $\gamma_{y} ; M_{p}$ is the moment when $\gamma$ reaches $4 \gamma_{y} ; t$ is the thickness of the panel zone; $b_{c}$ is the width of the column section; $f_{y}$ is the yield stress of the steel; $G$ is the shear modulus of the steel; and $E$ is the elastic modulus of the steel.

As shown in Figure 9, a beam element model (referred to as "BEM-K") with KCM was established based on the test model in Figure 1(a). To verify the accuracy of the KCM, the $B E M-K$ and the validated shell element model (referred to as "SEM") were analyzed, and the results were compared.

For the beam element model, it is difficult to separately define different material properties for the flange and web of an $\mathrm{H}$-section. Therefore, the material properties were changed to be identical for the flange and web based on the test results (Table 2), as shown in Table 4 .
TABLE 3: Reduction factor of the yield moment.

\begin{tabular}{lccc}
\hline & $M_{y j}(\mathrm{kN} \cdot \mathrm{m})$ & $\alpha_{\text {SEM }}$ & $\alpha$ \\
\hline$P_{c}=0$ & 124.4 & 1 & 1 \\
$P_{c}=0.2 P_{y c}$ & 120.6 & 0.969 & 0.980 \\
$P_{c}=0.5 P_{y c}$ & 109.0 & 0.876 & 0.866 \\
$P_{c}=0.7 P_{y c}$ & 97.4 & 0.783 & 0.714 \\
\hline
\end{tabular}

According to the geometric size of the beam-column connection and formulas (2)-(4), the spring properties of the $\mathrm{KCM}$ are calculated as shown in Table 5.

The curves of the load $F_{v}$ to the vertical displacement of point A were obtained (Figure 10) by analyzing the BEM-K and the SEM using the static nonlinear method. Figure 10 indicates that the KCM is able to accurately simulate the elastic behavior of the beam-column joint. However, in the elastic-plastic stage, the ultimate capacity of the BEM-K was higher than that of the SEM, and the joint deformation corresponding to the ultimate capacity was very small, which could not reflect the connection performance when the structure underwent a large deformation.

The main reasons for the simulation error of the KCM in the elastic-plastic stage are as follows: (a) The KCM assumes that the deformation and stiffness of the connection are only provided by the bending of the column flanges at four corners (Figure 5) in the elastic-plastic stage, and the effective angle was no more than $4 \gamma_{y}$, which was far less than the real deformation angle of the beam-column connection under large structural deformation. (b) According to the SEM analysis results, the actual stiffness of the beam-column connection is a comprehensive result of the shear stiffness of the panel zone and bending stiffness of the column flanges at four corners; however, $k_{p}$ of equation (2) is calculated only based on the bending stiffness of the column flanges without considering the shear stiffness of the panel zone in the elastic-plastic stage, which results in an obvious simulation error.

\subsection{Improved Constitutive Model of the Spring in the KCM.} Because the constitutive model of springs in the KCM (formulas (2)-(4)) cannot accurately reflect the plastic performance of the beam-column connection under large structural deformation, an improved constitutive model of springs was established based on the characteristics of the all-welded beam-column connection. The improved constitutive model is given as follows:

$$
\begin{aligned}
k & =\left\{\begin{array}{l}
k_{e}=0.95 d_{b} d_{c} t G, \quad\left(0<\gamma \leq \gamma_{y}\right), \\
k_{p}=G_{t}\left(d_{c}-2 t_{c f}\right) t\left(d_{b}-t_{s}\right)\left(\gamma_{y}<\gamma\right),
\end{array}\right. \\
M_{y} & =0.55 d_{b} d_{c} t f_{y} \sqrt{1-\left(P_{c} / P_{y c}\right)^{2}} .
\end{aligned}
$$

(a) The constitutive model of spring in the KCM can accurately simulate the elastic stiffness of the beamcolumn joint; therefore, the elastic stiffness $k_{e}$ of the improved constitutive model is the same as that of formula (2). However, the yield moment $M_{y}$ is 


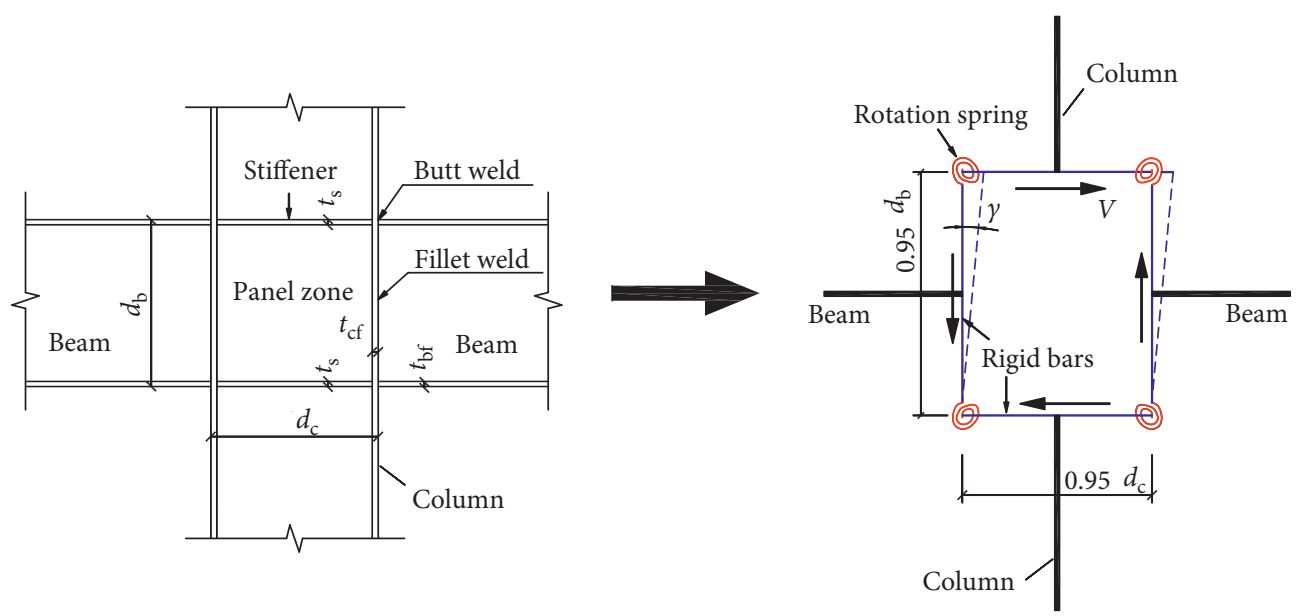

Figure 8: Schematic diagram of the KCM. Note. $d_{b}$ is the section height of the beam; $d_{c}$ is the section height of the column; $t_{b f}$ is the flange thickness of the beam; $t_{c f}$ is the flange thickness of the column; and $t_{s}$ is the thickness of the stiffness.

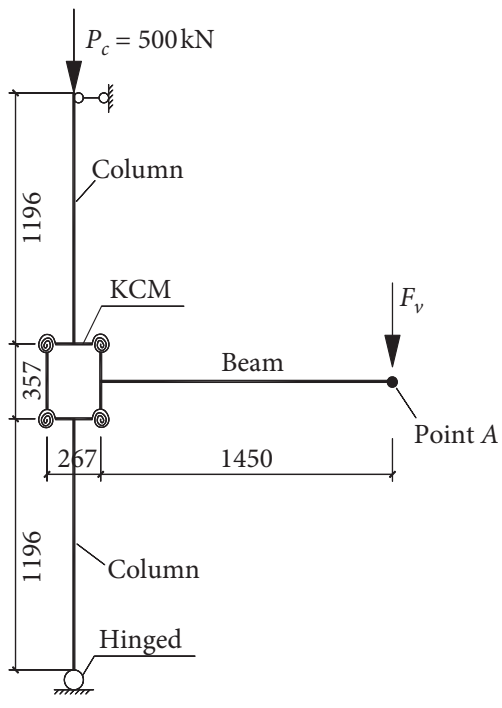

Figure 9: Diagram of the BEM-K (length unit: $\mathrm{mm}$ ).

TABLE 4: Material properties of the BEM-K and SEM.

\begin{tabular}{lccc}
\hline$E(\mathrm{GPa})$ & $f_{y}(\mathrm{MPa})$ & $f_{u}(\mathrm{MPa})$ & $\varepsilon_{u}$ \\
\hline 206 & 235 & 450 & 0.2 \\
\hline
\end{tabular}

TABLE 5: Spring properties of the KCM.

\begin{tabular}{lcccc}
\hline$k_{e}(\mathrm{kN} \cdot \mathrm{m})$ & $k_{p k}(\mathrm{kN} \cdot \mathrm{m})$ & $M_{y}(\mathrm{kN} \cdot \mathrm{m})$ & $M_{p}(\mathrm{kN} \cdot \mathrm{m})$ & $\gamma_{y}$ \\
\hline 18807 & 1243 & 32.3 & 38.8 & 0.00171 \\
\hline
\end{tabular}

modified to consider the influence of the column compression.

(b) The elastic-plastic stiffness $k_{p}$ of the improved constitutive model is the weighted result of the bending stiffness $k_{p k}$ of the column flanges and the shear stiffness $k_{p z}$ of the panel zone; that is,

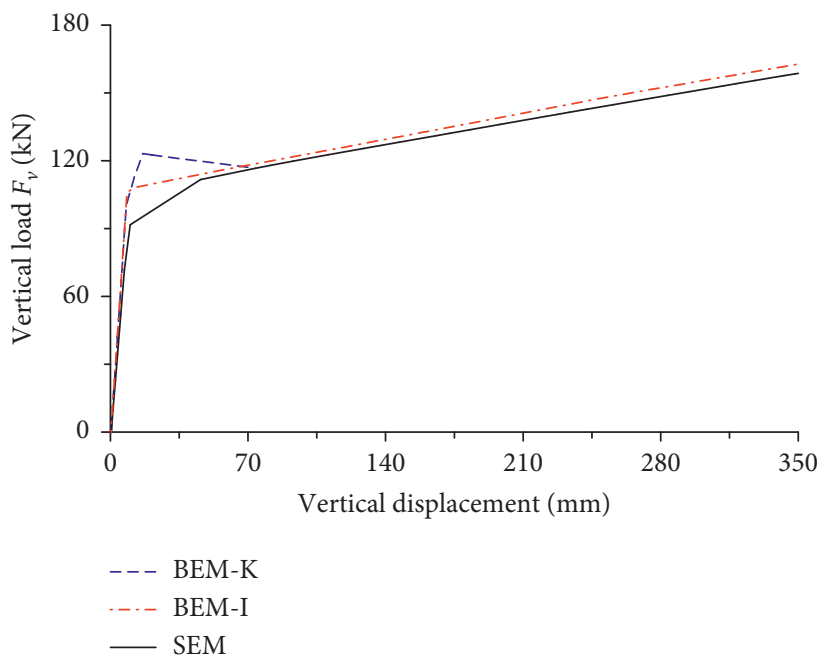

FIgURE 10: Load to vertical displacement curves of the BEM-K, BEM-I, and SEM.

$$
k_{p}=\beta k_{p k}+(1-\beta) k_{p z}, \quad\left(\gamma>\gamma_{y}\right)
$$

where $\beta$ is the weight coefficient. The analysis result indicates that the influence of the bending stiffness of the column flanges is very small compared to that of the panel zone. As a result, the improved elastic-plastic stiffness $k_{p}$ is approximately equal to $k_{p z}$, which is calculated as

$$
k_{p z}=\frac{M}{\gamma}=\frac{V}{\gamma}\left(d_{b}-t_{s}\right)=G_{t}\left(d_{c}-2 t_{c f}\right) t\left(d_{b}-t_{s}\right),
$$

where $G_{t}$ is the tangent shear modulus of the steel in the strengthening stage.

A new beam element model (referred to as "BEM-I") was established while the spring properties of the beam-column connection were modified according to equations (5) and (6). The modified spring properties are shown in Table 6. To validate the improved constitutive model, the BEM-I was 
TABLE 6: Improved spring properties of the connections in the BEM-I.

\begin{tabular}{lccc}
\hline$k_{e}(\mathrm{kN} \cdot \mathrm{m})$ & $k_{p}(\mathrm{kN} \cdot \mathrm{m})$ & $M_{y}(\mathrm{kN} \cdot \mathrm{m})$ & $\gamma_{y}$ \\
\hline 18807 & 84 & 32.3 & 0.00171 \\
\hline
\end{tabular}

analyzed with the static nonlinear method and compared with the SEM results, as depicted in Figure 10.

Figure 10 shows that the results of the BEM-I are close to those of the SEM, which indicates that the improved constitutive model can accurately simulate the behavior of the all-welded connections during large structural deformation.

\section{Parametric Analyses of the Beam- Column Assembly}

To further validate the performance of the improved composed-based model in structural progressive collapse analysis, a beam-column assembly was established based on the T-shape test model. As shown in Figure 11, the beamcolumn assembly consists of three columns and two beams, and the middle column is assumed to fail. The section sizes of the members are the same as those of the test model (Figure 1(a)). The net span of the beam is $5 \mathrm{~m}$.

4.1. Static Nonlinear Analysis of the Beam-Column Assembly. Three beam-column assembly models were established based on the computational model in Figure 11: (a) a shell element model referred to as "ASEM," (b) a beam element model (referred to as "ABEM-I") whose beam-column connections were simulated by the improved componentbased model, and (c) a beam element model (referred to as "ABEM-R") with an ideal rigid joint. The material properties of the three models are shown in Table 4, and the spring properties of the component-based model are the same as those in Table 5. Both compressions $P_{c 1}$ and $P_{c 2}$ were $500 \mathrm{kN}$.

A static nonlinear analysis on the three models was carried out by gradually increasing the load $\left(F_{v}\right)$ on the failed column, and the curves of the load $F_{v}$ to the vertical displacement of the failed column were obtained. As shown in Figure 12, the results of the three models in the elastic stage were almost the same; however, in the elastic-plastic stage, the capacity of the ABEM-R was higher than that of the other two models (at the same vertical displacement, the vertical load of the ABEM-R was $15 \%-25 \%$ higher than that of ASEM). As a result, the resistance of the steel frames would be overestimated when using the ideal rigid joint model in progressive collapse analysis.

However, the results of the ASEM and ABEM-I were very close in both the elastic and inelastic stages even when a remarkable axial tension $T$ was generated in the beam (usually referred to as the "catenary action").

4.2. Validation under Different Column Compressions. Based on the ASEM and ABEM-I, several cases of different compression on the side columns (Table 7) were analyzed to verify the accuracy of the improved component-based model. In Table 7, the column compressions of Cases 1 and 2 are distributed symmetrically, while the column compressions are asymmetrical for Cases 3 and 4 . The load-displacement curves of different column compression cases are depicted in Figure 13.

As shown in Figure 13, the structural behavior of the ABEM-I agrees well with that of the ASEM for Cases 1 to 4 except for the distinction at the end of the curves. The main reason for this distinction is the development of local buckling at the column flange in the ASEM (Figure 14), which cannot be reflected in the beam element model (ABEM-I).

Figure 13 also shows that the load-displacement curves of Cases 1 and 2 are similar to those of Cases 3 and Case 4, respectively, which indicates that the structural behavior is dominated by the larger column compression.

\subsection{Validation considering Different Beam-Column Stiffness} Ratios. By changing the thickness of the beam section (Table 8), the assembly in Figure 11 with different beamcolumn stiffness ratios (i.e., $\left(E I_{b} / l_{b}\right) /\left(E I_{c} / l_{c}\right)$, where $I_{b}$ and $I_{c}$ are the moments of inertia of the beam and column section, resp., and $l_{a}$ and $l_{b}$ are the lengths of the beam and column, resp.) was analyzed to verify the improved component-based model. Both column compressions $P_{c 1}$ and $P_{c 2}$ were $500 \mathrm{kN}$. The analysis results are shown in Figure 15.

In Figure 15, the analysis results of the ABEM-I are close to those of the ASEM, especially for Case 5. For Case 6, the capacity of the beam element model is approximately $8 \%$ higher than that of the shell element model.

\subsection{Dynamic Nonlinear Analysis of the Beam-Column} Assembly. As the collapse of a steel frame is a dynamic process, the dynamic analysis was also conducted to verify the performance of the improved component-based model. Based on the computational model in Figure 11, there were two steps in the dynamic analysis. (a) A support was set at the bottom of the middle column and the force $F_{v}$ that was $160 \mathrm{kN}$ (according to Figure 12, when $F_{v}$ reached $160 \mathrm{kN}$, the assembly structure underwent a vertical displacement $160 \mathrm{~mm}$ that was approximately $1 / 60$ of the span) was applied on the top; both compressions $P_{c 1}$ and $P_{c 2}$ were $500 \mathrm{kN}$. Then, the initial state of the beam-column assembly was obtained using quasistatic analysis. (b) Based on the explicit dynamic analysis method, the sudden column failure scenario was simulated by removing the support in a time of $0.007 \mathrm{~s}(1 / 10$ of the natural period of the structure [28]), and finally, the dynamic response of the remaining structure was acquired. The vertical displacement-time histories of the failed column were shown in Figure 16.

As depicted in Figure 16, the maximum vertical displacement of the ABEM-R is $170 \mathrm{~mm}$ that is apparently smaller than that of the ASEM $(360 \mathrm{~mm})$. However, the result of the ABEM-I is $348 \mathrm{~mm}$, which is close to the maximum vertical displacement of ASEM (the error is approximately $4 \%$ ). The comparison results are similar to that of static nonlinear analysis.

Based on the results of the parametric analyses, it can be found that the improved component-based model is capable 


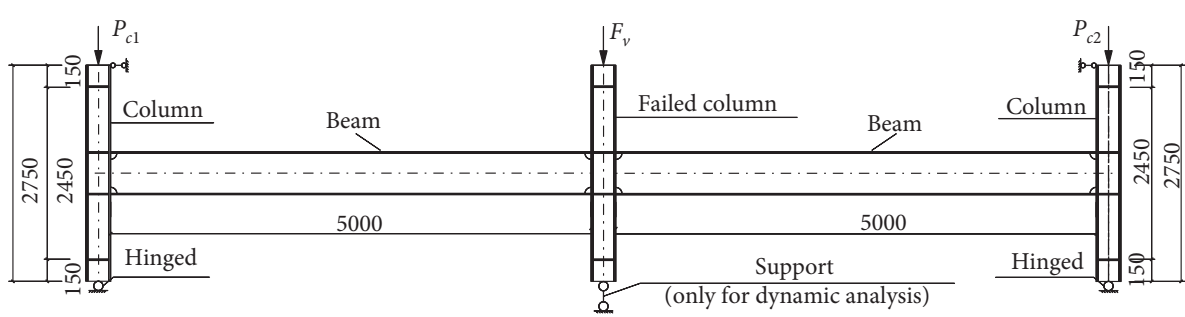

Figure 11: Computational model of the beam-column assembly (length unit: $\mathrm{mm}$ ).

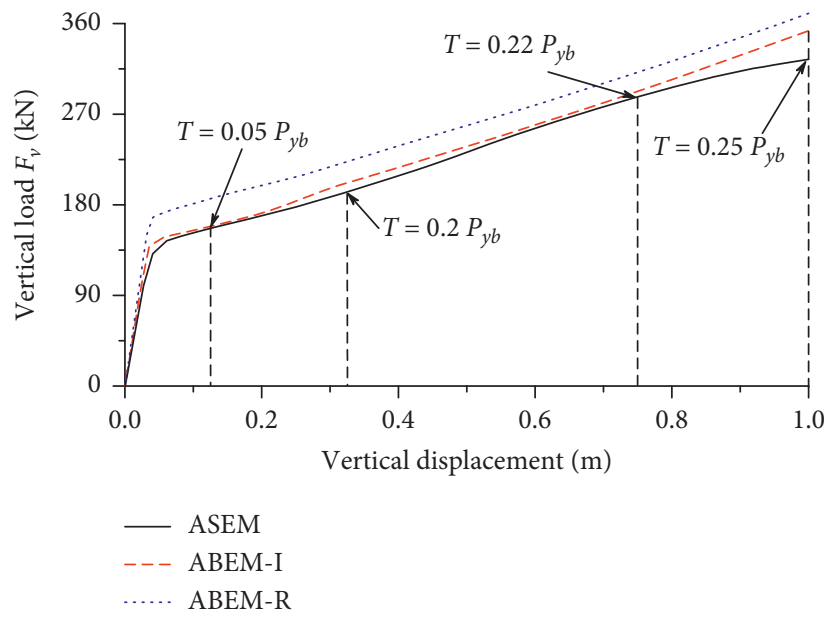

Figure 12: Static nonlinear analysis of three models. Note. $P_{y b}$ is the yield axial force of the beam.

TABLe 7: The cases of different column pressures.

\begin{tabular}{lcc}
\hline & $P_{c 1}(\mathrm{kN})$ & $P_{c 2}(\mathrm{kN})$ \\
\hline Case 1 & $0.5 P_{y c}$ & $0.5 P_{y c}$ \\
Case 2 & $0.7 P_{y c}$ & $0.7 P_{y c}$ \\
Case 3 & $0.2 P_{y c}$ & $0.5 P_{y c}$ \\
Case 4 & $0.2 P_{y c}$ & $0.7 P_{y c}$ \\
\hline
\end{tabular}

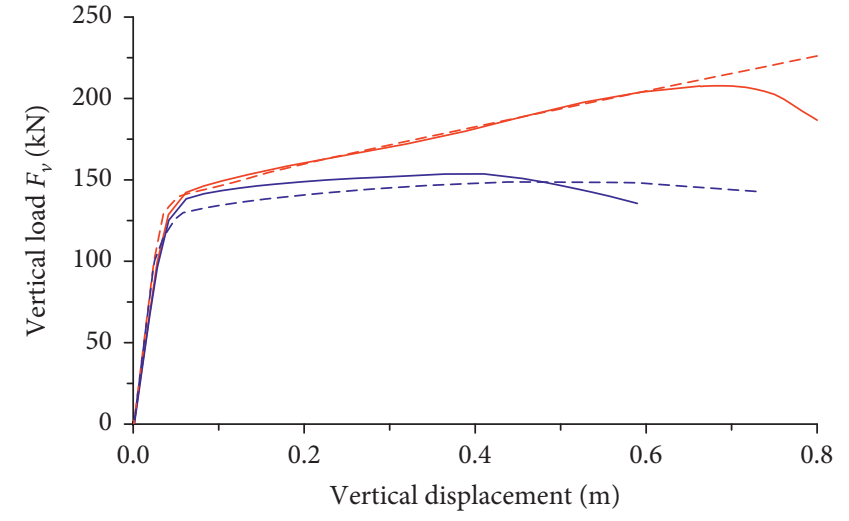

$\begin{array}{ll}-\operatorname{ASEM}(\text { Case 1) } & -\operatorname{ASEM}(\text { Case 2) } \\ ---\operatorname{ABEM}-\mathrm{I}(\text { Case } 1) & ---\operatorname{ABEM}-\mathrm{I}(\text { Case 2) }\end{array}$

(a)

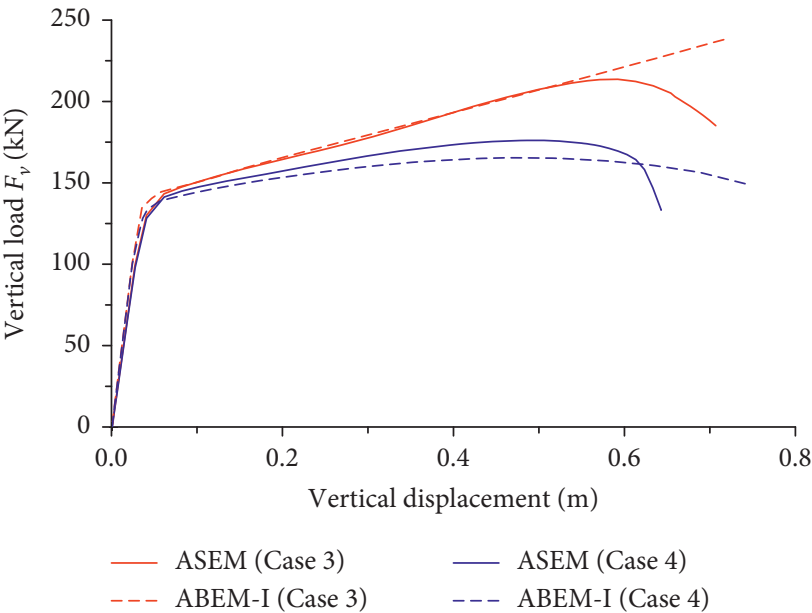

(b)

Figure 13: Load to vertical displacement curves of the ABEM-I and ASEM. (a) Cases 1 and 2. (b) Cases 3 and 4. 


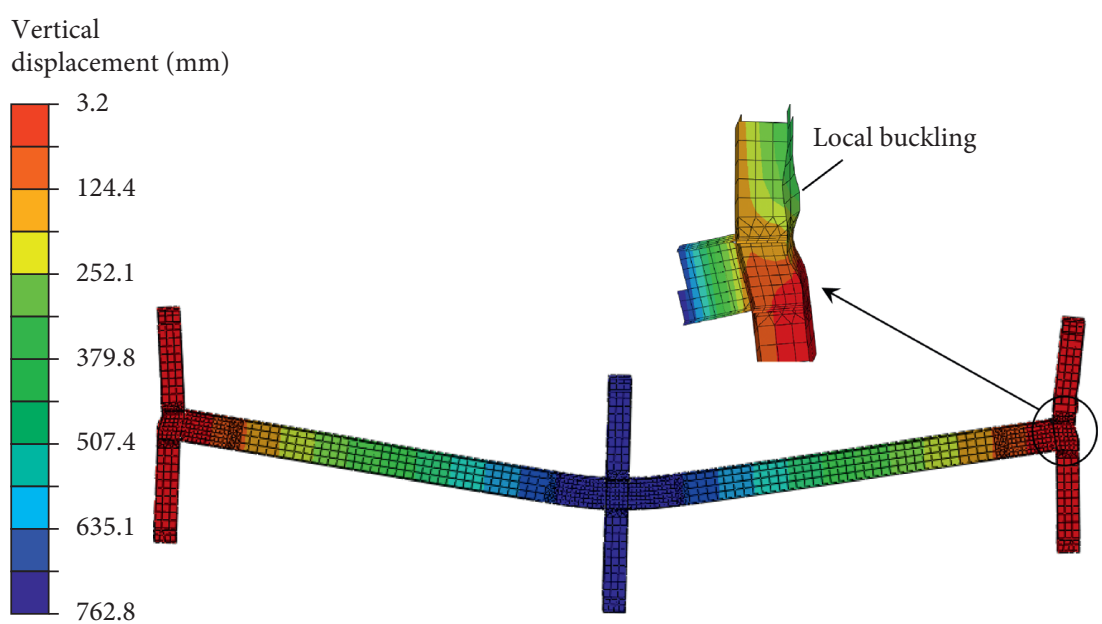

Figure 14: Deformation and local buckling of the ASEM (Case 3).

TABle 8: The modified thickness of the beam section.

\begin{tabular}{lcc}
\hline & Flange thickness $(\mathrm{mm})$ & Web thickness $(\mathrm{mm})$ \\
\hline Case 5 & 16 & 12 \\
Case 6 & 8 & 6
\end{tabular}

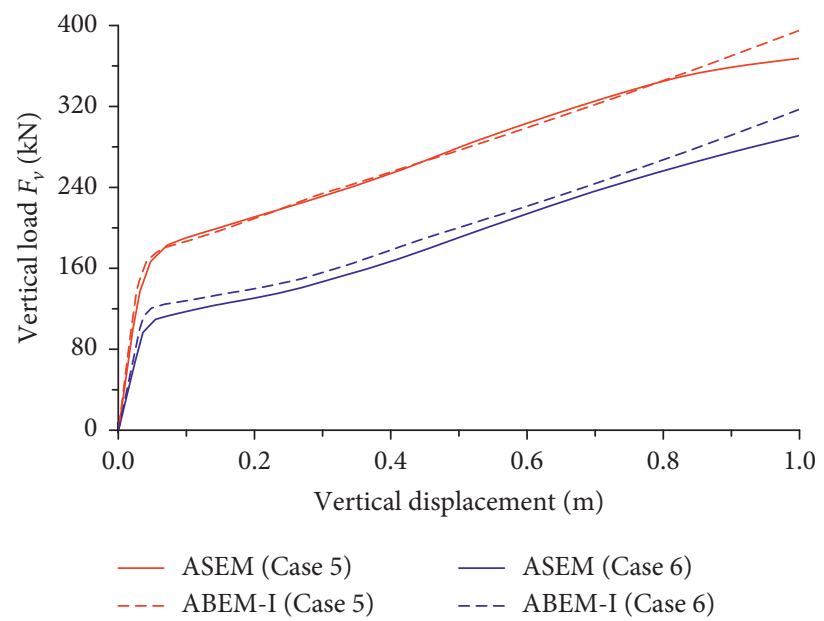

Figure 15: Load to vertical displacement curves of Cases 5 and 6.

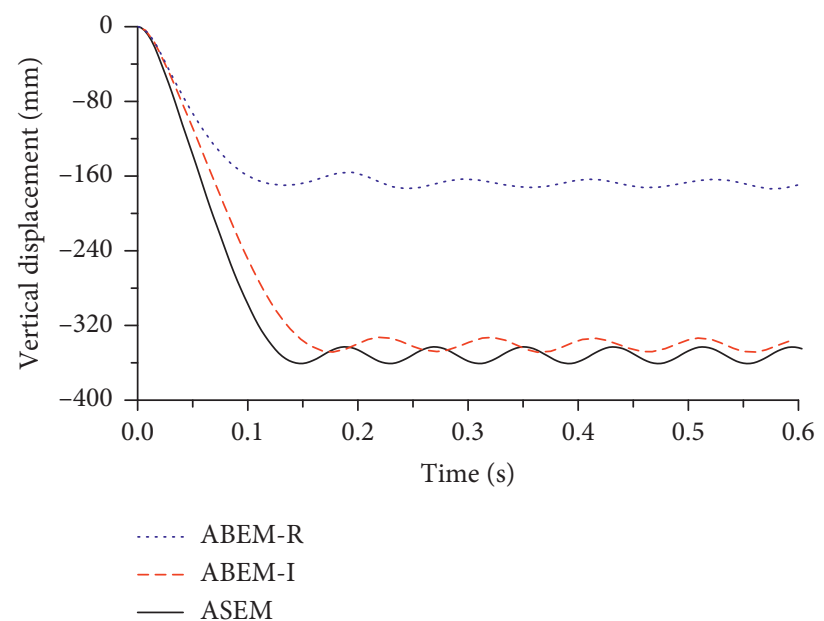

FIgURE 16: Vertical displacement-time histories of the failure column. 
of simulating the behavior of all-welded beam-column connections during large structural deformation.

\section{Conclusion}

The mechanical behavior of the all-welded beam-column connection during large structural deformation was investigated. An improved component-based joint model was proposed and validated by a series of parametric analyses. On the basis of the theoretical and numerical analyses, the findings of this research are summarized as follows:

(1) In the elastic-plastic stage, the stiffness of the allwelded beam-column connection is mainly provided by the bending stiffness of the column flange at four corners and the shear stiffness of the panel zone, and the latter is the dominant stiffness during large structural deformation.

(2) The compression of the column has a substantial impact on the behavior of the beam-column connection; that is, the larger the column pressure is, the lower the capacity and the ductility are.

(3) The theoretical reduction coefficient is accurate for a lower level of column compression (no more than $0.5 P_{y c}$ according to the analyses in this paper), but it becomes less accurate as the level of the column compression increases.

(4) The improved component-based model is capable of simulating the behavior of the all-welded beamcolumn connection when the structure undergoes a large deformation.

\section{Data Availability}

The data used to support the findings of this study are included within the article.

\section{Conflicts of Interest}

The authors declare that they have no conflicts of interest.

\section{Acknowledgments}

The study presented in this paper was supported by the National Natural Science Foundation of China (Grant no. 51608234), the Natural Science Foundation of Jiangsu Province of China (Grant no. BK20160534), and the Advanced Talents Scientific Research Foundation of Jiangsu University (13JDG067), which are gratefully acknowledged.

\section{References}

[1] J. M. Adam, F. Parisi, J. Sagaseta, and X. Lu, "Research and practice on progressive collapse and robustness of building structures in the 21st century," Engineering Structures, vol. 173, no. 1, pp. 122-149, 2018.

[2] B. A. Izzudin and A. G. Vlassis, "Progressive collapse of multistorey buildings due to sudden column loss-part1: simplified assessment framework," Engineering Structures, vol. 30, no. 5, pp. 1308-1318, 2008.
[3] J. Yu and K. H. Tan, "Numerical analysis with joint model on RC assemblages subjected to progressive collapse," Magazine of Concrete Research, vol. 66, pp. 1201-1208, 2016.

[4] M.-H. Tsai and Z.-K. You, "Experimental evaluation of inelastic dynamic amplification factors for progressive collapse analysis under sudden support loss," Mechanics Research Communications, vol. 40, pp. 56-62, 2012.

[5] M. Ferraioli, "A modal pushdown procedure for progressive collapse analysis of steel frame structures," Journal of Constructional Steel Research, vol. 156, pp. 227-241, 2019.

[6] W. Bao, J. Jiang, Y. Shao, and Y. Liu, "Experimental study of the lateral performance of a steel stud wall with a semi-rigid connected frame," Engineering Structures, vol. 183, pp. 677689, 2019.

[7] J. Jiang, Z. J. Ye, W. Bao et al., "Flexural buckling behaviour of $690 \mathrm{MPa}$ high strength steel h-section columns," Engineering Structures, vol. 200, Article ID 109718, 2019.

[8] G.-Q. Li, L.-L. Li, B. Jiang, and Y. Lu, "Experimental study on progressive collapse resistance of steel frames under a sudden column removal scenario," Journal of Constructional Steel Research, vol. 147, pp. 1-15, 2018.

[9] M. Alrubaidi, H. Elsanadedy, H. Abbas et al., "Investigation of different steel intermediate moment frame connections under column-loss scenario," Thin-Walled Structures, vol. 154, pp. 1-27, 2020.

[10] F. L. Wang, J. Yang, and Z. F. Pan, "Progressive collapse behavior of steel framed substructures with various beamcolumn connections," Engineering Failure Analysis, vol. 109, pp. 1-16, 2019.

[11] J. Jiang, S. P. Chiew, C. K. Lee, and P. L. Y. Tiong, "A numerical study on residual stress of high strength steel box column," Journal of Constructional Steel Research, vol. 128, no. 128, pp. 440-450, 2017.

[12] J. iang, W. Bao, Z. Y. Peng, Y. B. Wang, J. Liu, and X. H. Dai, "Experimental investigation on mechanical behaviours of TMCP high strength steel," Construction and Building Materials, vol. 200, pp. 664-680, 2019.

[13] J. Jiang, W. Bao, Z. Y. Peng et al., "Creep property of TMCP high strength steel Q690CFD at elevated temperatures," Journal of Materials in Civil Engineering (ASCE), vol. 32, no. 2, Article ID 04019364, 2020.

[14] H. S. Lew, J. A. Main, S. D. Robert et al., "Performance of steel moment connections under a column removal scenario. I: Experiments," Journal of Structural Engineering, vol. 139, no. 1, pp. 98-107, 2012.

[15] H. Y. Tang, X. Z. Deng, Y. G. Jia et al., "Study on the progressive collapse behavior of fully bolted RCS beam-to-column connections," Engineering Structures, vol. 199, no. 1, pp. 1-16, 2019.

[16] F. Dinu, I. Marginean, and D. Dubina, "Experimental testing and numerical modelling of steel moment-frame connections under column loss," Engineering Structures, vol. 151, no. 1, pp. 861-878, 2017.

[17] W. H. Zhong, Z. Tan, L. M. Tian et al., "Collapse resistance of composite beam-column assemblies with unequal spans under an internal column-removal scenario," Engineering Structures, vol. 206, no. 1, pp. 1-15, 2020.

[18] P. M. Stylianidis and D. A. Nethercot, "Modelling of connection behaviour for progressive collapse analysis," Journal of Constructional Steel Research, vol. 113, pp. 169-184, 2015.

[19] H. C. Yim and T. Krauthammer, "Mechanical properties of single-plate shear connections under monotonic, cyclic, and blast loads," Engineering Structures, vol. 37, pp. 24-35, 2012. 
[20] H. Krawinkler, "Shear in beam-column joints in seismic design of steel frames," Engineering Journal, vol. 15, no. 3, pp. 82-91, 1978.

[21] L. Tong, X. Huang, F. Zhou, and Y. Chen, "Experimental and numerical investigations on extremely-low-cycle fatigue fracture behavior of steel welded joints," Journal of Constructional Steel Research, vol. 119, pp. 98-112, 2016.

[22] K. Qian, X. Lan, Z. Li et al., "Progressive collapse resistance of two-storey seismic configured steel sub-frames using welded connections," Journal of Constructional Steel Research, vol. 170, pp. 1-18, 2020.

[23] B. Yang, H. Wang, Y. Yang, S.-B. Kang, X.-H. Zhou, and L. Wang, "Numerical study of rigid steel beam-column joints under impact loading," Journal of Constructional Steel Research, vol. 147, pp. 62-73, 2018.

[24] C.-H. Lee, S. Kim, K.-H. Han, and K. Lee, "Simplified nonlinear progressive collapse analysis of welded steel moment frames," Journal of Constructional Steel Research, vol. 65, no. 5, pp. 1130-1137, 2009.

[25] Z. S. Song, "Damage cumulation collapse mechanism and design ctriteria of welded steel beam-to-column connections under seismic load," M.S. thesis, Xi'an University of Architecture and Technology, Xi'an, China, 2001.

[26] J. Jiang, Z. Y. Peng, Z. J. Ye, and M. Ye, "Behaviour of $690 \mathrm{MPa}$ high strength steel built-up H-section columns under eccentric load scenarios," Engineering Structures, vol. 213, no. 213, Article ID 110550, 2020.

[27] J. Jiang, S. P. Chiew, C. K. Lee, and P. L. Y. Tiong, "An experimental study on residual stresses of high strength steel box columns," Journal of Constructional Steel Research, vol. 130, no. 130, pp. 12-21, 2017.

[28] General Services Administration, Progressive Collapse Analysis and Design Guidelines for New Federal Office Buildings and Major Modernization Projects, GSA, Washington, DC, USA, 2003. 